\title{
Reply to letter to the editor concerning: 'Correlation between clinical findings and esinophil/neutrophil ratio in patients with nasal polyps'
}

\author{
S. Hancer Tecimer ${ }^{1} \cdot$ F. Kasapoglu ${ }^{1}$ U. L. Demir ${ }^{1}$ O. A. Ozmen ${ }^{1}$. \\ H. Coskun ${ }^{1} \cdot$ O. Basut ${ }^{1}$
}

Received: 29 May 2015/Accepted: 9 June 2015/Published online: 19 June 2015

(C) Springer-Verlag Berlin Heidelberg 2015

\section{Dear Editor,}

We want to give a brief reply to those questions raised by that reader. (1) The endoscopic grading was done by the same author (Hancer Tecimer S.), thus there was no interpersonal variability with regard to Lund-Kennedy staging system. (2) The patients were operated by two senior surgeons (Kasapoglu F. and Demir U. L.). (3) We have already mentioned in the discussion section of the article that small sample size and relatively short follow-up duration might be the reasons why we found no difference at treatment outcomes between eosinophilic and neutrophilic patient groups. We have already indicated the necessity of further blinded and randomized clinical studies for a definite conclusion, in our manuscript. We are now studying on a similar randomized clinical study with equal number of sample sizes.

This reply refers to the comment available at doi:10.1007/s00405-015-3677-7.

U. L. Demir

uygardemir@hotmail.com

1 Department of Otolaryngology and Head and Surgery, Uludag University Medical School, Gorukle, 16059 Nilufer, Bursa, Turkey 